\title{
AVALIAÇÃO DE CULTIVARES DE ALFAFA E ESTIMATIVAS DE REPETIBILIDADE DE CARACTERES FORRAGEIROS ${ }^{1}$
}

\author{
REINALDO DE PAULA FERREIRA², MILTON DE ANDRADE BOTREL ${ }^{3}$, \\ ANTONIO VANDER PEREIRA ${ }^{2}$ e COSME DAMIÃO CRUZ ${ }^{4}$
}

\begin{abstract}
RESUMO - O objetivo deste trabalho foi avaliar o desempenho de 42 cultivares de alfafa (Medicago sativa L.) e estimar o coeficiente de repetibilidade das características produção de matéria seca, teor de proteína bruta na folha e no caule e tolerância a doenças, avaliadas no período das águas (outubro a março) e da seca (abril a setembro), em seis cortes. Observou-se variabilidade significativa entre as cultivares quanto à produção de matéria seca e ao teor de proteína bruta na folha, em ambas as estações. No tocante a teor de proteína bruta no caule e tolerância a doenças, a variabilidade foi manifestada apenas no período da seca. As cultivares de melhor desempenho, para a maioria das características avaliadas, foram Crioula e Cibola. Em geral, o coeficiente de repetibilidade apresentou estimativas de baixa magnitude (inferior a 0,4). Quanto à produção de matéria seca, constatou-se a existência de comportamento similar das cultivares avaliadas nos dois períodos estudados, coeficiente de repetibilidade variando de 0,3195 a 0,4270 , determinação genotípica em torno de $65 \%$, e possibilidade de se atingir a predição do valor real por meio de sete a nove cortes.
\end{abstract}

Termos para indexação: forrageira, melhoramento, correlações.

\section{EVALUATION OF ALFALFA CULTIVARS AND ESTIMATES OF REPEATABILITY COEFFICIENT OF FORAGE TRAITS}

\begin{abstract}
The objective of this study was to evaluate the performance of 42 cultivars of alfalfa (Medicago sativa L.) and to estimate the repeatability coefficient for dry matter production, leaf and stem protein content and disease tolerance features during the dry (April to September) and rainy (October to March) seasons with six cuts. Dry matter yield and leaf protein content presented significant variation in both seasons, although stem protein content and tolerance to diseases were different only during the dry season. Cultivars Crioula and Cibola had the best performance in most features. In general, the repeatability coefficient showed a low magnitude estimate (below 0,40). Regarding dry matter production, the cultivars showed similar behavior in both seasons, with repeatability coefficient ranging from 0.3195 to 0.4270 , genotypic determination around $65 \%$ and the possibility to predict the real value after seven to nine cuts.
\end{abstract}

Index terms: forage, breeding, correlation.

\section{INTRODUÇÃO}

O custo e a qualidade da alimentação constituem os fatores básicos que determinam a possibilidade de incremento da produtividade do rebanho leiteiro

\footnotetext{
${ }^{1}$ Aceito para publicação em 23 de julho de 1998.

${ }^{2}$ Eng. Agr., Dr., Embrapa-Centro Nacional de Pesquisa de Gado de Leite (CNPGL), Rua Eugênio do Nascimento, 610, CEP 36038-330 Juiz de Fora, MG. E-mail: ferreira@cnpgl.embrapa.br

${ }^{3}$ Eng. Agr., M.Sc., Embrapa-CNPGL.

${ }^{4}$ Eng. Agr., Dr., Prof. Titular, Dep. Biologia Geral, Univ. Fed. Viçosa, CEP 36570-000 Viçosa, MG.
}

de elevado padrão genético. Tem sido crescente o interesse pelo uso da alfafa em sistemas intensivos de produção de leite, dada a sua qualidade, produtividade e resposta econômica em relação a outros tipos de alimentos volumosos. As formas mais comuns da sua utilização têm sido o feno, a silagem e o pastejo.

Em alfafa e outras espécies forrageiras perenes são procuradas características morfológicas, fisiológicas e agronômicas que maximizem o rendimento, a qualidade da forragem e a persistência das plantas, nas suas diversas formas de utilização. O potencial de produção de matéria seca da alfafa é em 
torno de 25 t/ha/ano. Este potencial não é atingido, na maioria das situações, por motivo de limitações edafoclimáticas (Fontes et al.,1993; Paim, 1994).

Para identificação de cultivares de alfafa mais adaptadas a um determinado ambiente, são necessárias avaliações periódicas, por meio de cortes, de modo a mensurar o comportamento das principais características fenotípicas. Assim, pode-se estimar a variabilidade genotípica entre o material disponível e a repetibilidade do desempenho de cada cultivar ou progênie. Segundo Falconer (1987), quando várias medidas de um mesmo caráter são feitas em cada indivíduo, a variância fenotípica poderá ser parcelada, servindo para quantificar o ganho em precisão, pela repetição das medidas, e esclarecer a natureza da variação causada pelo ambiente.

Nos ensaios envolvendo progênies ou cultivares, avaliadas em sucessivos cortes, é possível estimar os coeficientes de repetibilidade das variáveis estudadas, quantificando-se o número necessário de determinações que devem ser realizadas em um caráter para se obter uma avaliação fenotípica mais eficiente e de menor custo de mão-de-obra. Valores altos, para a estimativa da repetibilidade do caráter, indicam que é possível predizer o valor real do indivíduo com um número relativamente pequeno de medições (Cruz \& Regazzi, 1994).

Além disso, a repetibilidade expressa o valor máximo que a herdabilidade pode atingir, pois expressa a proporção da variância fenotípica, que é atribuída às diferenças genéticas confundidas com os efeitos permanentes que atuam na cultivar ou progênie. Assim, a repetibilidade, à semelhança da herdabilidade, constitui instrumento indispensável para orientar os trabalhos de melhoramento.

O objetivo deste trabalho foi avaliar o desempenho de cultivares de alfafa, e estimar o coeficiente de repetibilidade das características produção de matéria seca, teor de proteína bruta na folha e no caule e tolerância a doenças, avaliadas no período das águas (outubro a março) e da seca (abril a setembro).

\section{MATERIAL E MÉTODOS}

Foram avaliadas 42 cultivares de alfafa, em ensaio conduzido na Estação Experimental da Embrapa-Centro Nacional de Pesquisa de Gado de Leite, em Coronel
Pacheco, MG. O delineamento utilizado foi o de blocos ao acaso, com três repetições, tendo as parcelas as dimensões de $3 \times 2 \mathrm{~m}$. Os cortes foram realizados na área útil $\left(3,6 \mathrm{~m}^{2}\right)$ de cada parcela, com base no estádio de desenvolvimento das plantas. Assim, sempre que cada cultivar atingisse $10 \%$ de floração ou quando iniciasse o processo de desenvolvimento das brotações basais, procedia-se ao corte, a $5 \mathrm{~cm}$ do nível do solo.

Avaliaram-se as características produção de matéria seca no período das águas (PMSA) e da seca (PMSS), teor de proteína bruta nas folhas no período das águas (PBFA) e da seca (PBFS), teor de proteína bruta no caule no período das águas (PBCA) e da seca (PBCS) e tolerância a doenças no período das águas (TDA) e da seca (TDS). Estimou-se a tolerância a doenças, adotando-se as notas $0=$ tolerante (ausência de danos); $1=$ moderadamente tolerante (presença esporádica de danos); 2 = moderadamente sensível (presença de danos, causando, aparentemente, pequenos prejuízos à planta); e 3 = sensível (presença generalizada de danos, causando sérios prejuízos).

As análises foram feitas a partir da média das repetições. O período de avaliação foi caracterizado em duas épocas (águas, de outubro a março, e seca, de abril a setembro). Em cada época, foram realizados três cortes. O modelo estatístico utilizado foi:

$\mathrm{Y}_{\mathrm{ij}}=\mu+\mathrm{G}_{\mathrm{i}}+\mathrm{C}_{\mathrm{j}}+\varepsilon_{\mathrm{ij}}$

em que:

$\mathrm{Y}_{\mathrm{ij}}=$ média da i-ésima cultivar no j-ésimo corte;

$\mu=$ média geral do ensaio;

$\mathrm{G}_{\mathrm{i}}=$ efeito da i-ésima cultivar confundido com as influências permanentes do ambiente (corte);

$\mathrm{C}_{\mathrm{j}}=$ efeito do j-ésimo corte;

$\varepsilon_{\mathrm{ij}}=$ efeito aleatório que envolve outras causas de variação não incluídas no modelo.

O coeficiente de repetibilidade (r) foi estimado por três procedimentos estatísticos, de tal forma que seja possível avaliar a consistência da estimativa, permitindo conclusões mais confiáveis sobre o parâmetro estudado. Os estimadores dos coeficientes de repetibilidade utilizados são descritos a seguir.

\section{Método da análise de variância}

$$
r \frac{\operatorname{Covv}\left(Y_{i j}, Y_{i j^{\prime}}\right)}{\sqrt{\hat{V}\left(Y_{i j}\right) \hat{V}\left(Y_{i j^{\prime}}\right)}}=\frac{\hat{\phi}_{g}}{\hat{\phi}_{g}+\hat{\sigma}^{2}}
$$

sendo: $\hat{\phi}_{\mathrm{g}}=(\mathrm{QMG}-\mathrm{QMR}) / \mathrm{n} \quad$ e $\quad \hat{\sigma}^{2}=\mathrm{QMR}$

em que:

$\mathrm{QMG}=$ quadrado médio associado ao efeito da cultivar; 
$\mathrm{QMR}=$ quadrado médio associado à variação aleatória; $\mathrm{n}=$ número de cortes efetuados $(\mathrm{n}=3)$.

\section{Método dos componentes principais}

Esta estimativa é obtida a partir da matriz de correlação entre valores de populações obtidas em cada par de medições obtido nos cortes. Por este método obtêm-se os autovalores e autovetores normalizados de R. O autovetor, cujos elementos apresentam o mesmo sinal e magnitudes próximas, é aquele que expressa a tendência das populações em manter suas posições relativas nos vários intervalos de corte (Abeywardena, 1972). Com base neste autovalor, estima-se o coeficiente de repetibilidade (Rutledge, 1974):

$\mathrm{r}=\frac{\hat{\lambda}_{1}-1}{\mathrm{n}-1}$

em que:

$\hat{\lambda}_{1}=$ autovalor associado ao autovetor $\mathrm{R}$, cujos elementos têm o mesmo sinal e magnitudes semelhantes.

Alternativamente, o coeficiente de repetibilidade foi estimado a partir das matrizes de variância e covariância (T), sendo, neste caso, o estimador de repetibilidade dado por:

$\mathrm{r}=\frac{\hat{\lambda}_{1}-\hat{\sigma}_{\mathrm{Y}}^{2}}{\hat{\sigma}_{\mathrm{y}}^{2}(\mathrm{n}-1)}$

sendo:

$\hat{\sigma}_{\mathrm{y}}^{2}=\hat{\phi}_{\mathrm{g}}^{2}+\hat{\sigma}^{2}$

$\hat{\lambda}_{1}=$ autovalor associado ao autovetor $\mathrm{T}$, cujos elementos têm o mesmo sinal e magnitudes semelhantes.

\section{Método da análise estrutural}

Esta estimativa foi obtida conforme proposto por Mansour et al. (1981), dada por:

$\mathrm{r}=\frac{\alpha^{\prime} \mathrm{R} \alpha-1}{\mathrm{n}-1}$

sendo:

$\alpha^{\prime}=$ autovetor com elementos paramétricos, associado ao maior autovalor da matriz de correlação uniforme, dado

por $\alpha^{\prime}=\left[\frac{1}{\sqrt{\mathrm{n}}} \cdots \frac{1}{\sqrt{\mathrm{n}}}\right]$.

O número mínimo de medições necessárias para predizer o valor real dos indivíduos, com base em um coefi- ciente de determinação $\left(\mathrm{R}^{2}\right)$ pré-estabelecido $(0,80,0,90$ e 0,95), foi calculado por Cruz \& Regazzi (1994):

$\mathrm{n}_{\mathrm{o}}=\frac{\mathrm{R}^{2}(1-\mathrm{r})}{\left(1-\mathrm{R}^{2}\right) \mathrm{r}}$

em que:

$\mathrm{n}_{\mathrm{o}}=$ número de medições para predição do valor real;

$\mathrm{r}=$ coeficiente de repetibilidade obtido de acordo com uma das diferentes metodologias utilizadas.

Todas as análises estatísticas foram realizadas utilizando o programa computacional GENES (Cruz, 1997).

\section{RESULTADOS E DISCUSSÃO}

$\mathrm{Na}$ Tabela 1 são apresentados os resultados da análise de variância das características estudadas. Detectaram-se diferenças estatísticas quanto às características, exceto no tocante a teor de proteína bruta no caule e tolerância a doenças, no período das águas. A existência de variabilidade significativa reflete a heterogeneidade do material genético estudado, indicando a possibilidade de identificação de materiais promissores.

Observaram-se diferenças significativas $(\mathrm{P}<0,01)$ entre as cultivares quanto ao potencial para produção de matéria seca, tanto no período das águas como no período da seca (Tabela 2). Durante a estação das águas, a produção de matéria seca por corte variou de $1.584 \mathrm{~kg} / \mathrm{ha}$ (cv. Maxidor) a $805 \mathrm{~kg} / \mathrm{ha}$ (cv. NK Pierce). A produção média, considerando todas as cultivares avaliadas, foi de $1.220 \mathrm{~kg} / \mathrm{ha} /$ corte.

Quanto ao rendimento de forragem no período seco, os valores extremos observados foram: $1.356 \mathrm{~kg} / \mathrm{ha}$ (cv. Crioula) e $639 \mathrm{~kg} / \mathrm{ha}$ (cv. NK Pierce). Considerando todas as cultivares avaliadas, deduz-se que a produção média/corte durante a seca correspondeu a, aproximadamente, $78 \%$ da produção observada no período das águas (Tabela 1).

Observaram-se diferenças significativas $(\mathrm{P}<0,05)$ entre as cultivares quanto à concentração de proteína bruta nas folhas durante a estação das águas, que variou de $35,40 \%$ (cv. P-105) a 27,27\% (cv. Seriver) (Tabela 2). Na época da seca, não se observou diferença significativa $(\mathrm{P}>0,05)$ na concentração de proteína bruta nas folhas, que foi, em média, 15,3\%, considerando-se todas as cultivares avaliadas. $\mathrm{Ob}$ - 
TABELA 1. Análise de variância dos caracteres produção de matéria seca nas águas (PMSA) e na seca (PMSS), teor de proteína bruta nas folhas (PBFA) e caule (PBCA) nas águas (PBFA), teor de proteína bruta nas folhas (PBFS) e caule (PBCS) na seca e tolerância a doenças nas águas (TDA) e na seca (TDS).

\begin{tabular}{lccccccccc}
\hline Fonte de & GL & \multicolumn{10}{c}{ QM } \\
\cline { 2 - 9 } variação & & PMSA & PMSS & PBFA & PBCA & PBFS & PBCS & TDA & TDS \\
\hline Cortes & 2 & 43903,238 & 203431,812 & 2,387 & 34,427 & 5,001 & 51,614 & 0,341 & 0,627 \\
Genótipos & 41 & $139967,218^{* *}$ & $70006,828^{* *}$ & $6,984^{* *}$ & $8,150^{* *}$ & $2,623^{\text {ns }}$ & $11,921^{*}$ & $0,719^{\text {ns }}$ & $0,424^{*}$ \\
Resíduo & 82 & 53128,605 & 29062,933 & 2,711 & 3,831 & 1,748 & 6,761 & 0,301 & 0,261 \\
\hline Média & & 1219,9 & 961,5 & 31,1 & 32,5 & 15,3 & 21,4 & 2,2 & 2,1 \\
CV (\%) & 18,9 & 17,7 & 5,3 & 6,0 & 8,6 & 12,1 & 25,1 & 24,5 \\
\hline
\end{tabular}

$*$, ** Significativo a $5 \%$ e $1 \%$ de probabilidade, respectivamente, pelo teste $\mathrm{F}$.

servaram-se diferenças significativas no teor de proteína bruta do caule, considerando o teste de Tukey, somente na estação das águas, que variou, nessa época do ano, de $37,4 \%$ (cv. ARC) a 28,23\% (cv. Mecca). Na estação da seca, o teor médio de proteína bruta no caule foi de $21,4 \%$. Os resultados, tanto de produção de matéria seca como de proteína bruta, demonstram que a alfafa constitui importante fonte de volumoso para vacas de alta produtividade, principalmente durante a estação da seca, superando em produção e valor nutritivo as forrageiras tropicais, que, mesmo sob condições de irrigação, nessa época do ano, apresentam grande queda no rendimento forrageiro ( Alvim et al.,1986; Botrel et al., 1991).

As doenças mais freqüentemente observadas foram a mancha-foliar-amarela e a antracnose, causadas pelos fungos Leptotrochila medicaginis e Colletotrichum trifolii. Embora não tenha havido diferenças significativas entre as cultivares quanto à tolerância a essas doenças, observou-se uma tendência de as cultivares Cibola e ARC serem mais tolerantes (Tabela 2).

As estimativas de correlação entre as características estudadas são apresentadas na Tabela 3. Correlação entre uma mesma característica avaliada nos dois períodos, seca e águas, além de refletir associação de natureza genética e ambiental, medem indiretamente a interação genótipos x ambientes. Segundo Cruz \& Castoldi (1991), a interação genótipos $\mathrm{x}$ ambientes pode ser atribuída a duas causas: a complexa e a simples. A causa simples é determinada pela diferença de variação entre os genótipos quando avaliados em diferentes ambientes. A complexa é atribuída à falta de correlação entre os valores fenotípicos destes genótipos avaliados nos ambientes.

A correlação entre peso da matéria seca no período das águas e da seca foi de 0,668 , o que indica concordância satisfatória do desempenho das cultivares nesses dois períodos. De fato, como pode ser observado na Tabela 1, entre as 10 melhores cultivares em cada ambiente, sete são concordantes. Assim, apesar de os valores fenotípicos médios terem sido alterados com a época, a posição relativa foi, de certa forma, mantida, sugerindo que a seleção, em relação a esta característica, possa ser praticada em qualquer uma das épocas consideradas. Neste caso, poderá se proceder a seleção com menor risco de descarte de material genético superior.

Para as demais variáveis, a correlação entre períodos, apesar de ter sido positiva, foi de baixa magnitude. $\mathrm{O}$ fato de as variáveis proteína bruta no caule e tolerância a doenças não terem apresentado diferença significativa na época das águas, tornam as estimativas do coeficiente de correlação sem grande utilidade e com interpretações questionáveis. Entretanto, as baixas correlações entre proteína bruta no caule e tolerância a doenças $(r=0,049$ nas águas e $r=-0,085$ na seca) são indicativas de um comportamento diferencial das cultivares avaliadas, necessitando, portanto, de critérios de seleção mais cuidadosos. 
Outro aspecto interessante é o fato de a produção de matéria seca ter apresentado correlação negativa $(\mathrm{r}=-0,432$ nas águas e $\mathrm{r}=-0,464$ na seca $)$ significativa, com o teor de proteína bruta no caule. Este fato ocorreu tanto no período das águas quanto no da seca. Uma possível explicação para o fato seria a diluição do teor de proteína do caule, resultante do acúmulo da matéria seca.

As variáveis TDA e TDS, que expressam a tolerância à doença, mostraram correlação negativa com

TABELA 2. Produção de matéria seca (PMS), teor de proteína bruta na folha e no caule e tolerância a doenças (TD) de cultivares de alfafa, avaliadas na época das águas e da seca ${ }^{1}$.

\begin{tabular}{|c|c|c|c|c|c|c|c|c|}
\hline \multirow[t]{3}{*}{ Cultivares } & \multicolumn{2}{|c|}{ PMS (kg/ha/corte) } & \multicolumn{4}{|c|}{ Proteína bruta } & \multicolumn{2}{|c|}{$\mathrm{T} \mathrm{D}$} \\
\hline & \multirow[t]{2}{*}{ Águas } & \multirow[t]{2}{*}{ Seca } & \multicolumn{2}{|c|}{ Águas } & \multicolumn{2}{|c|}{ Seca } & \multirow[t]{2}{*}{ Águas } & \multirow[t]{2}{*}{ Seca } \\
\hline & & & Folha & Caule & Folha & Caule & & \\
\hline Maxidor & $1584,66 \mathrm{a}$ & $978,67 \mathrm{abcd}$ & $32,10 \mathrm{abc}$ & $14,13 \mathrm{a}$ & $31,67 \mathrm{abc}$ & $19,17 \mathrm{a}$ & $2,00 \mathrm{a}$ & $2,33 a$ \\
\hline P-105 & $1504,67 \mathrm{ab}$ & $965,00 \mathrm{abcd}$ & $35,40 \mathrm{a}$ & $16,60 \mathrm{a}$ & $33,67 \mathrm{abc}$ & $21,20 \mathrm{a}$ & $1,67 \mathrm{a}$ & $1,33 \mathrm{a}$ \\
\hline Fortineira & $1395,33 \mathrm{ab}$ & $893,00 \mathrm{abcd}$ & $31,80 \mathrm{abc}$ & $15,03 \mathrm{a}$ & $34,40 \mathrm{abc}$ & $23,13 \mathrm{a}$ & $2,00 \mathrm{a}$ & $2,00 \mathrm{a}$ \\
\hline Moapa & $1454,00 \mathrm{ab}$ & $1052,33 \mathrm{abcd}$ & $32,33 a b c$ & $13,97 \mathrm{a}$ & $32,96 a b c$ & $20,06 a$ & $2,67 \mathrm{a}$ & $2,33 a$ \\
\hline Cal West & $1564,67 \mathrm{ab}$ & $1081,67 \mathrm{abcd}$ & $30,83 \mathrm{abc}$ & $14,80 \mathrm{a}$ & $34,17 \mathrm{abc}$ & $20,47 \mathrm{a}$ & $2,00 \mathrm{a}$ & $2,00 \mathrm{a}$ \\
\hline WL 605 & $1533,00 \mathrm{ab}$ & $1212,00 \mathrm{abc}$ & $30,50 \mathrm{abc}$ & $13,27 \mathrm{a}$ & $32,87 \mathrm{abc}$ & $19,60 \mathrm{a}$ & $2,67 \mathrm{a}$ & $2,00 \mathrm{a}$ \\
\hline Monarca & $1516,67 \mathrm{ab}$ & $1132,33 \mathrm{abcd}$ & $32,47 \mathrm{abc}$ & $14,23 \mathrm{a}$ & $32,63 \mathrm{abc}$ & $22,07 \mathrm{a}$ & $2,00 \mathrm{a}$ & $2,33 a$ \\
\hline CUF 101 & $1559,00 \mathrm{ab}$ & $1067,33 \mathrm{abcd}$ & $30,97 \mathrm{abc}$ & $14,47 \mathrm{a}$ & $32,80 \mathrm{abc}$ & $21,57 \mathrm{a}$ & $2,00 \mathrm{a}$ & $2,00 \mathrm{a}$ \\
\hline CW 187 & $1284,00 \mathrm{ab}$ & $974,67 \mathrm{abcd}$ & $32,17 \mathrm{abc}$ & $14,06 \mathrm{a}$ & $32,83 \mathrm{abc}$ & $19,73 a$ & $2,33 \mathrm{a}$ & $2,33 a$ \\
\hline Pionner & $896,00 \mathrm{ab}$ & $773,00 \mathrm{~cd}$ & $29,53 \mathrm{bc}$ & $15,90 \mathrm{a}$ & $34,50 \mathrm{abc}$ & $21,33 a$ & $2,33 \mathrm{a}$ & $2,33 a$ \\
\hline Crioula & $1522,33 \mathrm{ab}$ & $1256,67 \mathrm{abc}$ & $30,50 \mathrm{abc}$ & $13,60 \mathrm{a}$ & $32,36 \mathrm{abc}$ & $17,90 \mathrm{a}$ & $1,33 \mathrm{a}$ & $2,00 \mathrm{a}$ \\
\hline Saladina & $1233,00 \mathrm{ab}$ & $938,33 \mathrm{abcd}$ & $30,76 \mathrm{abc}$ & $13,93 \mathrm{a}$ & $31,60 \mathrm{abc}$ & $19,17 \mathrm{a}$ & $2,67 \mathrm{a}$ & $2,00 \mathrm{a}$ \\
\hline P 5229 & $965,33 \mathrm{ab}$ & $781,67 \mathrm{bcd}$ & $31,03 \mathrm{abc}$ & $14,80 \mathrm{a}$ & $32,73 \mathrm{abc}$ & $19,97 \mathrm{a}$ & $2,67 \mathrm{a}$ & $2,33 a$ \\
\hline Varsat & $1071,67 \mathrm{ab}$ & $910,00 \mathrm{abcd}$ & $31,70 \mathrm{abc}$ & $16,13 \mathrm{a}$ & $30,23 b c$ & $24,27 \mathrm{a}$ & $2,00 \mathrm{a}$ & $1,67 \mathrm{a}$ \\
\hline Painé & $1088,67 \mathrm{ab}$ & $776,33 \mathrm{bcd}$ & $32,07 \mathrm{abc}$ & $15,87 \mathrm{a}$ & $35,20 \mathrm{ab}$ & $24,13 \mathrm{a}$ & $2,00 \mathrm{a}$ & $2,00 \mathrm{a}$ \\
\hline WL 318 & $1228,33 \mathrm{ab}$ & $994,33 \mathrm{abcd}$ & $31,20 \mathrm{abc}$ & $15,53 \mathrm{a}$ & $34,10 \mathrm{abc}$ & $21,17 \mathrm{a}$ & $1,33 \mathrm{a}$ & $1,67 \mathrm{a}$ \\
\hline Aurora & $1117,33 \mathrm{ab}$ & $924,33 \mathrm{abcd}$ & $31,87 \mathrm{abc}$ & $16,07 \mathrm{a}$ & $34,33 \mathrm{abc}$ & $22,17 \mathrm{a}$ & $2,67 \mathrm{a}$ & $2,67 \mathrm{a}$ \\
\hline CW 86 & $1148,33 \mathrm{ab}$ & $872,67 \mathrm{abcd}$ & $31,53 \mathrm{abc}$ & $15,83 \mathrm{a}$ & $32,40 \mathrm{abc}$ & $20,70 \mathrm{a}$ & $2,67 \mathrm{a}$ & $2,00 \mathrm{a}$ \\
\hline Victória & $1331,67 \mathrm{ab}$ & $936,67 \mathrm{abcd}$ & $30,90 \mathrm{abc}$ & $14,97 \mathrm{a}$ & $32,87 \mathrm{abc}$ & $20,93 a$ & $1,67 \mathrm{a}$ & $2,00 \mathrm{a}$ \\
\hline Trifecta & $1247,00 \mathrm{ab}$ & $965,00 \mathrm{abcd}$ & $30,33 a b c$ & $15,47 \mathrm{a}$ & $32,07 \mathrm{abc}$ & $20,27 \mathrm{a}$ & $2,00 \mathrm{a}$ & $1,67 \mathrm{a}$ \\
\hline P 555 & $1257,67 \mathrm{ab}$ & $826,00 \mathrm{abcd}$ & $30,33 \mathrm{abc}$ & $15,63 \mathrm{a}$ & $32,43 \mathrm{abc}$ & $21,37 \mathrm{a}$ & $2,67 \mathrm{a}$ & $2,33 a$ \\
\hline Sequel & $1165,33 \mathrm{ab}$ & $876,67 \mathrm{abcd}$ & $28,97 \mathrm{bc}$ & $14,63 \mathrm{a}$ & $29,47 \mathrm{bc}$ & $19,23 \mathrm{a}$ & $2,67 \mathrm{a}$ & $2,33 a$ \\
\hline P 205 & $1088,00 \mathrm{ab}$ & $852,67 \mathrm{abcd}$ & $30,53 \mathrm{abc}$ & $15,57 \mathrm{a}$ & $32,30 \mathrm{abc}$ & $22,77 \mathrm{a}$ & $2,33 \mathrm{a}$ & $2,00 \mathrm{a}$ \\
\hline Maricopa & $1180,67 \mathrm{ab}$ & $750,67 \mathrm{~cd}$ & $32,07 \mathrm{abc}$ & $16,57 \mathrm{a}$ & $31,17 \mathrm{abc}$ & $22,40 a$ & $3,00 \mathrm{a}$ & $2,67 \mathrm{a}$ \\
\hline $\mathrm{ARC}$ & $1181,33 \mathrm{ab}$ & $856,33 \mathrm{abcd}$ & $31,77 \mathrm{abc}$ & $15,87 \mathrm{a}$ & $37,40 \mathrm{a}$ & $26,07 \mathrm{a}$ & $1,33 \mathrm{a}$ & $1,33 a$ \\
\hline CW 8746 & $1331,00 \mathrm{ab}$ & $911,33 \mathrm{abcd}$ & $31,03 \mathrm{abc}$ & $15,80 \mathrm{a}$ & $33,30 \mathrm{abc}$ & $20,83 a$ & $1,67 \mathrm{a}$ & $2,00 \mathrm{a}$ \\
\hline CW 8754 & $1210,33 \mathrm{ab}$ & $989,67 \mathrm{abcd}$ & $29,40 \mathrm{bc}$ & $15,13 \mathrm{a}$ & $31,73 \mathrm{abc}$ & $23,27 \mathrm{a}$ & $2,33 a$ & $2,67 \mathrm{a}$ \\
\hline Victória & $1119,33 \mathrm{ab}$ & $947,67 \mathrm{abcd}$ & $30,90 \mathrm{abc}$ & $15,87 \mathrm{a}$ & $32,40 \mathrm{abc}$ & $24,60 \mathrm{a}$ & $2,33 \mathrm{a}$ & $2,00 \mathrm{a}$ \\
\hline Pardenave & $1228,67 \mathrm{ab}$ & $935,00 \mathrm{abcd}$ & $32,03 \mathrm{abc}$ & $17,33 \mathrm{a}$ & $33,47 \mathrm{abc}$ & $23,70 \mathrm{a}$ & $2,67 \mathrm{a}$ & $1,67 \mathrm{a}$ \\
\hline Mecca & $1118,00 \mathrm{ab}$ & $918,00 \mathrm{abcd}$ & $30,53 \mathrm{abc}$ & $17,37 \mathrm{a}$ & $30,23 \mathrm{abc}$ & $18,63 \mathrm{a}$ & $2,67 \mathrm{a}$ & $2,67 \mathrm{a}$ \\
\hline $\mathrm{UC/CUF}$ & $907,33 \mathrm{ab}$ & $739,67 \mathrm{~cd}$ & $29,27 b c$ & $15,87 \mathrm{a}$ & $28,23 \mathrm{c}$ & $22,63 a$ & $3,00 \mathrm{a}$ & $2,67 \mathrm{a}$ \\
\hline NK Pierce & $805,33 b$ & $639,67 d$ & $29,83 \mathrm{bc}$ & $15,63 \mathrm{a}$ & $30,33 b c$ & $23,93 a$ & $3,00 \mathrm{a}$ & $2,67 \mathrm{a}$ \\
\hline Seriver & $983,67 \mathrm{ab}$ & $826,00 \mathrm{abcd}$ & $27,27 \mathrm{c}$ & $15,30 \mathrm{a}$ & $32,20 \mathrm{abc}$ & $21,20 \mathrm{a}$ & $2,33 a$ & $2,00 \mathrm{a}$ \\
\hline Crioula & $1525,33 \mathrm{ab}$ & $1356,33 \mathrm{a}$ & $29,03 \mathrm{bc}$ & $14,87 \mathrm{a}$ & $31,50 \mathrm{abc}$ & $18,70 \mathrm{a}$ & $1,67 \mathrm{a}$ & $1,67 \mathrm{a}$ \\
\hline CW 4468 & $972,67 \mathrm{ab}$ & $1126,67 \mathrm{abcd}$ & $31,80 \mathrm{abc}$ & $14,90 \mathrm{a}$ & $31,40 \mathrm{abc}$ & $20,60 \mathrm{a}$ & $2,00 \mathrm{a}$ & $2,33 a$ \\
\hline Cordobesa & $1102,33 \mathrm{ab}$ & $1065,33 \mathrm{abcd}$ & $32,13 \mathrm{abc}$ & $15,07 \mathrm{a}$ & $33,67 \mathrm{abc}$ & $23,43 a$ & $1,67 \mathrm{a}$ & $1,67 \mathrm{a}$ \\
\hline Humperfield & $894,33 \mathrm{ab}$ & $944,00 \mathrm{abcd}$ & $27,37 \mathrm{c}$ & $15,27 \mathrm{a}$ & $33,70 \mathrm{abc}$ & $22,97 \mathrm{a}$ & $2,00 \mathrm{a}$ & $2,33 a$ \\
\hline Weeviccheck & $1121,33 \mathrm{ab}$ & $1018,00 \mathrm{abcd}$ & $33,43 \mathrm{ab}$ & $16,90 \mathrm{a}$ & $34,50 \mathrm{abc}$ & $24,93 a$ & $1,33 a$ & $1,67 \mathrm{a}$ \\
\hline Trifecta & $966,00 \mathrm{ab}$ & $976,33 \mathrm{abcd}$ & $33,50 \mathrm{ab}$ & $16,00 \mathrm{a}$ & $32,43 \mathrm{abc}$ & $21,10 \mathrm{a}$ & $3,00 \mathrm{a}$ & $2,33 a$ \\
\hline Monarca & $1119,67 \mathrm{ab}$ & $1062,33 \mathrm{abcd}$ & $30,80 \mathrm{abc}$ & $15,23 \mathrm{a}$ & $31,07 \mathrm{abc}$ & $21,07 \mathrm{a}$ & $2,33 \mathrm{a}$ & $2,33 a$ \\
\hline Cibola & $1557,33 \mathrm{ab}$ & $1340,67 \mathrm{ab}$ & $31,50 \mathrm{abc}$ & $15,63 \mathrm{a}$ & $31,50 \mathrm{abc}$ & $17,97 \mathrm{a}$ & $1,33 \mathrm{a}$ & $1,33 a$ \\
\hline Crioula & $1156,00 \mathrm{ab}$ & $938,00 \mathrm{abcd}$ & $32,83 \mathrm{ab}$ & $14,80 \mathrm{a}$ & $31,30 \mathrm{abc}$ & $19,20 \mathrm{a}$ & $2,33 a$ & $2,00 \mathrm{a}$ \\
\hline
\end{tabular}

${ }^{1}$ Médias seguidas pelas mesmas letras, na vertical, não diferem estatisticamente, a $5 \%$ de probabilidade, pelo teste Tukey. 
todas as demais características estudadas. Como, na avaliação dessas características, se adotou uma escala em que o menor valor expressava a tolerância e o maior a susceptibilidade (presença generalizada de danos, causando sérios prejuízos), conclui-se que as cultivares com maior produção de matéria seca e de proteína bruta foram as que manifestaram maior tolerância a doenças. Em relação aos diferentes períodos de avaliação, detectou-se correlação de 0,707 no que tange a esta característica. Assim, há certa concordância do desempenho das cultivares em relação ao ataque de doenças, porém a seleção praticada no período da seca deve ser enfatizada, uma vez que neste período a variabilidade genotípica foi mais pronunciada.

Na Tabela 4 são apresentadas as estimativas do coeficiente de repetibilidade obtidas pelos diferentes procedimentos estatísticos. Em geral, houve boa

TABELA 3. Estimativa de correlação dos caracteres produção de matéria seca nas águas (PMSA) e na seca (PMSS), teor de proteína bruta nas folhas nas águas (PBFA) e na seca (PBFS), teor de proteína bruta no caule nas águas (PBCA) e na seca (PBCS) e tolerância a doenças nas águas (TDA) e na seca (TDS).

\begin{tabular}{lccccccl}
\hline Caráter & PMSS & PBFA & PBFS & PBCA & PBCS & TDA & TDS \\
\hline PMSA & $0,668^{* *}$ & 0,283 & 0,154 & $-0,434^{* *}$ & $-0.432^{* *}$ & $-0,395^{* *}$ & $-0,368^{*}$ \\
PMSS & & 0,115 & 0,030 & $-0,420^{* *}$ & $-0,464^{* *}$ & $-0,531^{* *}$ & $-0,385^{*}$ \\
PBFA & & & 0,295 & 0,186 & 0,100 & $-0,222$ & $-0,298$ \\
PBFS & & & & 0,069 & $0,378^{*}$ & $-0,483^{* *}$ & $-0,427^{* *}$ \\
PBCA & & & & & $0,478^{* *}$ & 0,049 & $-0,095$ \\
PBCS & & & & & & $-0,029$ & $-0,085$ \\
TDA & & & & & & & $0,707^{* *}$ \\
\hline
\end{tabular}

*,** Significativo a 5 e $1 \%$ de probabilidade, respectivamente, pelo teste $\mathrm{t}$.

TABELA 4. Estimativa da repetibilidade dos caracteres produção de matéria seca nas águas (PMSA) e na seca (PMSS), teor de proteína bruta nas folhas nas águas (PBFA) e na seca (PBFS), teor de proteína bruta no caule nas águas (PBCA) e na seca (PBCS) e tolerância a doenças nas águas (TDA) e na seca (TDS) ${ }^{1}$.

\begin{tabular}{|c|c|c|c|c|c|}
\hline \multirow[t]{2}{*}{ Caráter } & \multirow[t]{2}{*}{ ANOVA } & \multicolumn{2}{|c|}{ Componentes principais } & \multicolumn{2}{|c|}{ Análise estrutural } \\
\hline & & Covariância & Correlação & Covariância & Correlação \\
\hline PMSA & $\begin{array}{l}0,3527 \\
(62,04)\end{array}$ & $\begin{array}{l}0,4270 \\
(69,09)\end{array}$ & $\begin{array}{l}0,3577 \\
(62,56)\end{array}$ & $\begin{array}{l}0,3527 \\
(62,04)\end{array}$ & $\begin{array}{l}0,3438 \\
(61,12)\end{array}$ \\
\hline PMSS & $\begin{array}{l}0,3195 \\
(58,48)\end{array}$ & $\begin{array}{l}0,3850 \\
(65,25)\end{array}$ & $\begin{array}{l}0,3199 \\
(58,52)\end{array}$ & $\begin{array}{l}0,3195 \\
(58,48)\end{array}$ & $\begin{array}{l}0,3117 \\
(57,61)\end{array}$ \\
\hline PBFA & $\begin{array}{l}0,3444 \\
(61,18)\end{array}$ & $\begin{array}{l}0,4189 \\
(68,38)\end{array}$ & $\begin{array}{l}0,3710 \\
(63,89)\end{array}$ & $\begin{array}{l}0,3443 \\
(61,17)\end{array}$ & $\begin{array}{l}0,3695 \\
(63,74)\end{array}$ \\
\hline PBFS & $\begin{array}{c}0,2731 \\
(52,99)\end{array}$ & $\begin{array}{l}0,3141 \\
(57,87)\end{array}$ & $\begin{array}{l}0,3089 \\
(57,28)\end{array}$ & $\begin{array}{l}0,2730 \\
(52,98)\end{array}$ & $\begin{array}{l}0,3037 \\
(56,69)\end{array}$ \\
\hline PBCA & $\begin{array}{l}0,1429 \\
(33,34)\end{array}$ & $\begin{array}{l}0,2272 \\
(46,86)\end{array}$ & $\begin{array}{l}0,1571 \\
(35,87)\end{array}$ & $\begin{array}{l}0,1430 \\
(33,35)\end{array}$ & $\begin{array}{l}0,1348 \\
(31,84)\end{array}$ \\
\hline PBCS & $\begin{array}{c}0,2028 \\
(43,29)\end{array}$ & $\begin{array}{l}0,3508 \\
(61,84)\end{array}$ & $\begin{array}{l}0,2636 \\
(51,77)\end{array}$ & $\begin{array}{l}0,2028 \\
(43,28)\end{array}$ & $\begin{array}{l}0,2156 \\
(45,19)\end{array}$ \\
\hline TDA & $\begin{array}{c}0,3168 \\
(58,17)\end{array}$ & $\begin{array}{l}0,3668 \\
(63,48)\end{array}$ & $\begin{array}{l}0,3181 \\
(58,32)\end{array}$ & $\begin{array}{l}0,3168 \\
(58,17)\end{array}$ & $\begin{array}{l}0,3148 \\
(57,95)\end{array}$ \\
\hline TDS & $\begin{array}{r}0,1719 \\
(38,37) \\
\end{array}$ & $\begin{array}{l}0,1741 \\
(38,74) \\
\end{array}$ & $\begin{array}{r}0,1798 \\
(39,66) \\
\end{array}$ & $\begin{array}{l}0,1719 \\
(38,37) \\
\end{array}$ & $\begin{array}{r}0,1748 \\
(38,86) \\
\end{array}$ \\
\hline
\end{tabular}

${ }^{1}$ Valores entre parêntesis referem-se ao coeficiente de determinação associado ao coeficiente de repetibilidade. 
concordância entre as estimativas obtidas pelos diferentes métodos, conferindo-lhes maior confiabilidade.

As baixas estimativas do coeficiente de repetibilidade, de maneira geral inferior a 0,4 , ressaltam as dificuldades existentes para o melhorista em identificar os melhores valores genotípicos a partir da análise das médias fenotípicas obtidas, considerando-se apenas os três cortes efetuados em cada época. A predição do valor real, expressa pelo coeficiente de determinação, é inferior a $70 \%$, o que indica que a superioridade ou inferioridade do comportamento das cultivares pode não ser mantida. Há necessidade de realizar medições adicionais, de modo a garantir maior confiabilidade ao processo de seleção. Outra alternativa é a melhoria das condições experimentais, de tal forma que se possa detectar as reais diferenças entre as cultivares a partir de um menor número de medições.

Na Tabela 5 encontram-se as estimativas do número de medições necessárias para se ter diferentes valores de predição do valor real da população (ou coeficiente de determinação), obtidos a partir dos coeficientes de repetibilidade estimados pelo método dos componentes principais, baseado na matriz de correlação. Percebe-se a necessidade de se realizar de sete a nove cortes, para obter predições com confiabilidade em torno de $80 \%$, para as caracterís-

TABELA 5. Número de medições associado a vários coeficientes de determinação $\left(R^{2}\right)$, estimado para os caracteres produção de matéria seca nas águas (PMSA) e na seca (PMSS), teor de proteína bruta nas folhas nas águas (PBFA) e na seca (PBFS), teor de proteína bruta no caule nas águas (PBCA) e na seca (PBCS) e tolerância a doenças nas águas (TDA) e na seca (TDS).

\begin{tabular}{lcrrr}
\hline Caracteres & Repetibilidade & $\mathrm{R}^{2}=0,80$ & $\mathrm{R}^{2}=0,90$ & $\mathrm{R}^{2}=0,95$ \\
\hline PMSA & 0,3577 & 7,18 & 16,16 & 34,12 \\
PMSS & 0,3199 & 8,50 & 19,13 & 40,39 \\
PBFA & 0,3700 & 6,81 & 15,32 & 32,35 \\
PBFS & 0,3089 & 8,95 & 20,14 & 42,51 \\
PBCA & 0,1571 & 21,46 & 48,29 & 101,94 \\
PBCS & 0,2636 & 11,17 & 25,14 & 53,08 \\
TDA & 0,3181 & 8,57 & 19,29 & 40,73 \\
TDS & 0,1798 & 18,25 & 41,06 & 86,67 \\
\hline
\end{tabular}

ticas produção de matéria seca e teor de proteína bruta na folha, no período das águas e da seca. Elevar esse coeficiente de determinação, mantendo-se as condições de controle ambiental atual, é praticamente inviável, por demandar um número relativamente grande de medições (Tabela 5).

Além disso, verificou-se que para as demais características (PBC e TD, tanto nas águas quanto na seca) a confiabilidade do processo de seleção e descarte do material é reduzida. Quanto a estas características, a predição de $80 \%$ só é atingida com mais de 12 medições, que certamente implicará maiores custos e emprego de mão-de-obra. Assim, um maior controle ambiental, seja por manejo, seja por experimentação mais apropriada, deverá ser implementado no programa em desenvolvimento.

\section{CONCLUSÕES}

1. Detecta-se variabilidade significativa entre as cultivares para produção de matéria seca e teor de proteína bruta na folha, nos períodos das águas e da seca; para teor de proteína bruta no caule e tolerância a doenças, a variabilidade é manifestada apenas no período da seca.

2. Os coeficientes de repetibilidade das características são relativamente baixos (inferiores a 0,4); a predição do valor real das cultivares em cada época é inferior a $70 \%$, indicando a necessidade de maior controle ambiental ou maior número de avaliações (cortes), para que a seleção possa ser praticada com maior confiabilidade.

3. O aumento do número de avaliações por meio de oito a dez cortes é recomendado, possibilitando obter precisão do valor genético acima de $80 \%$, para as características produção de matéria seca e teor de proteína bruta na folha.

\section{REFERÊNCIAS}

ABEYWARDENA, V. An application of component analysis in genetics. Journal of Genetics, Bangalore, v.61, p.27-51, 1972.

ALVIM, M.J.; BOTREL, M.A.; NOVELLY, P.E. Produção de gramíneas tropicais e temperadas, irrigadas na época da seca. Revista da Sociedade Brasileira de Zootecnia, Viçosa, MG, v.15, n.5, p.384-392, 1986.

Pesq. agropec. bras., Brasília, v.34, n.6, p.995-1002, jun. 1999 
BOTREL, M. de A.; ALVIM, M.J.; XAVIER, D.J. Efeito da irrigação sobre algumas características agronômicas de cultivares de capim-elefante. Pesquisa Agropecuária Brasileira, Brasília, v.26, n.10, p.1731-1736, out. 1991.

CRUZ, C.D. Programa GENES - Aplicativo computacional em genética e estatística. Viçosa, MG: UFV, 1997. 442p.

CRUZ, C.D.; CASTOLDI, F. Decomposição da interação genótipos $\mathrm{x}$ ambientes em partes simples e complexa. Revista Ceres, MG, Viçosa, v.38, p.422-430, 1991.

CRUZ, C.D.; REGAZZI, A.J. Modelos biométricos aplicados ao melhoramento genético. Viçosa, MG: UFV, Impr. Univ., 1994. 390p.

FALCONER, D.S. Introdução à genética quantitativa. Viçosa, MG: UFV, Impr. Univ., 1987. 279p.
FONTES, P.C.R.; MARTINS, C.E.; CÓSER, A.C.; VILELA, D. Produção e níveis de nutrientes em alfafa (Medicago sativa L.) no primeiro ano de cultivo na Zona da Mata de Minas Gerais. Revista da Sociedade Brasileira de Zootecnia, Viçosa, MG, v.22, n.2, p.205-211, 1993.

MANSOUR, H.; NORDHEIM, E.V.; RUTLEDGE, J.J. Estimations of repeatability. Theoretical Applied Genetic, v.60, p.151-156, 1981.

PAIM, N.R. Utilização e melhoramento da alfafa. In: WORKSHOP SOBRE O POTENCIAL FORRAGEIRO DE ALFAFA (MEDICAGO SATIVA L.) NOS TRÓPICOS, 1994, Juiz de Fora. Juiz de Fora: Embrapa-CNPGL, 1994. p.141-147.

RUTLEDGE, J.J. A scaling which removes bias of Abeywardena's estimator of repeatability. Journal of Genetics, Bangalore, v.61, p.247-250, 1974. 